\title{
AS PUBLICAÇÕES DO INSTAGRAM COMO ATIVADORES DO CONSUMO DE USUÁRIOS
}

Maria Naftally Dantas Barbosa ${ }^{1}$

Yákara Vasconcelos Pereira ${ }^{2}$

Karla Rosane Do Amaral Demoly ${ }^{1}$

\footnotetext{
${ }^{1}$ Universidade Federal Rural do Semi-Árido

${ }^{2}$ Universidade Federal de Pernambuco - UFPE
} 


\section{AS PUBLICAÇÕES DO INSTAGRAM COMO ATIVADORES DO CONSUMO DE USUÁRIOS}

Resumo: Este artigo tem o objetivo de identificar se o consumo pode ser ativado no Instagram. A abordagem do comportamento do consumidor nas redes sociais e o processo de ativação (priming) integram a base teórica da pesquisa. Um estudo de caso qualitativo foi realizado com os usuários ativos em duas etapas, por meio de uma entrevista coletiva e entrevistas individuais. Trinta e três sujeitos participaram das entrevistas semiestruturadas, que foram examinadas por meio da análise de conteúdo com apoio do software Atlas.ti. Os resultados apontam a possibilidade dos estímulos compartilhados na rede social Instagram serem responsáveis por impulsionar a ativação do consumo de forma consciente, sendo possível perceber a sua influência nos comportamentos subsequentes. Esta pesquisa contribuirá para a tomada de decisão de empreendedores que operam no ambiente online, permitindo-os obter conhecimentos acerca dos estímulos ativadores e sua atuação na mente do consumidor, para que possam utilizá-los em suas estratégias empresariais.

Palavras-chave: Ativação do Consumo. Comportamento do Consumidor. Redes Sociais. Instagram.

\section{$1 \quad$ Introdução}

Os avanços tecnológicos, a rapidez da transmissão e a facilidade de acesso aos computadores contribuíram consideravelmente para ampliar o uso da internet, possibilitando ainda o crescimento do número de pessoas e países conectados, além de atualização de equipamentos e dispositivos, como os aparelhos móveis (HERMIDA et al., 2011).

Além de facilitar e expandir os espaços de comunicação entre os usuários, as tecnologias de internet, conhecidas como Web 2.0, têm estimulado o envolvimento do público na observação, seleção, interpretação e compartilhamento das informações. É importante compreender a Web 2.0 como a segunda geração de serviços online, que potencializa os processos coletivos, a troca afetiva, a produção e circulação de informações e a construção social do conhecimento tomando por base a informática (PRIMO, 2007).

Nesse contexto, é por meio da conversação mediada que são estabelecidas trocas informacionais que dão origem às redes sociais da internet ou redes sociais digitais (RECUERO, 2009). De acordo com Hermida et al. (2011), os usuários dos sites têm uma forma objetiva de se comunicar e se expressam como uma espécie de alto-falante, referindo-se à quantidade de pessoas que alcançam em pouco tempo e à atenção que conseguem proporcionar ao conteúdo da mensagem.

Uma das redes sociais que mais cresce mundialmente é o Instagram (DJAFAROVA; RUSHWORTH, 2016). O aplicativo foi fundado em 2010 e consiste em uma rede social que permite aos usuários capturar e compartilhar imagens e vídeos de maneira instantânea virtualmente. Entre as funções da rede é possível destacar a capacidade dos usuários em adicionar descrições, hashtags, mencionar outros usuários e inserir localizações e links em suas publicações (CASALÓ; FLAVIAN; IBAÑEZ, 2017; HU et al., 2014).

Com isso, a pesquisa está centrada nas publicações do Instagram como ativadores do consumo, visto que, o conhecimento partilhado online nas redes sociais, seja por texto, foto ou 
vídeo, possui valor (HEINONEN, 2011). Vale salientar ainda que, as recomendações de consumo, bem como a preferência por determinado produto, serviço e marca divulgada via mensagens mediadas pelas redes de relacionamentos têm efeitos significativos nos julgamentos e sobre uma possível decisão de compra de outros usuários (DI PIETRO; PANTANO, 2012), aspectos que podem contribuir para ativar o consumo.

O processo de ativação é um aspecto recorrente do efeito priming (MINTON, CORNWELL; KAHLE, 2016), constituído por táticas de influência e persuasão que desencadeiam determinadas respostas automáticas, conscientes (intencionais) ou inconscientes (não-intencionais) (DIJKSTERHUIS et al., 2005). Pode ser descrito como um conjunto de estímulos externos que levam à ativação de algum conceito, ideia e estereótipos, mediante apresentação de um objeto ou situação específica, provocando nos indivíduos comportamentos subsequentes (FAZIO et al., 1986; MARTIN; MORICH, 2011). Assim, os efeitos priming podem ser responsáveis por ativar ou alterar a percepção e o comportamento dos consumidores, bem como suas atitudes e crenças por meio de fatores dentro e fora do controle consciente.

Dessa forma, entende-se que o consumo de produtos/serviços pode ser ativado em uma rede social no momento em que os objetos de interesse são expostos e armazenados na memória. Isso acontece porque antes mesmo dos consumidores tomarem uma decisão, eles já são preparados para o momento da compra (MIRSCH; LEHRER; JUNG, 2017).

A partir da realização de um levantamento bibliográfico, nota-se que pesquisas anteriores trataram da ativação na perspectiva da psicologia do consumidor (FAZIO et al., 1986; DIJKSTERHUIS et al., 2005; MARTIN; MORICH, 2011; PACHECO JÚNIOR; DAMACENA; BRONZATTI, 2015) para investigar os sentidos voltados à exposição de anúncios publicitários na mídia impressa sobre o comportamento de consumo. Sendo assim, embora seja um assunto do cotidiano da sociedade contemporânea, observa-se poucos estudos sobre o processo de ativação do consumo no contexto das redes sociais digitais, onde os usuários interagem diretamente com o conteúdo gerado por outro usuário. Diante disso, o problema de pesquisa foi assim definido: as publicações do Instagram podem ativar o consumo de usuários? Para tanto, o artigo tem por objetivo apresentar os resultados do estudo que buscou identificar se o consumo pode ser ativado no Instagram.

Como justificativa teórica, esta pesquisa prioriza as bases teóricas que abordam o processo de ativação do consumo em seu contexto virtual (PACHECO JÚNIOR; DAMACENA; BRONZATTI, 2015), podendo ser utilizada em investigações futuras que envolvam o comportamento do consumidor em redes sociais como o Instagram e os estímulos favoráveis ao consumo.

No contexto do comportamento do consumidor nas redes sociais digitais, o processo de ativação deve ser melhor estudado, com o objetivo de compreender os estímulos que ativam o consumo nos usuários, uma vez que podem ser utilizados para melhorar as ações de marketing, publicidade, e, consequentemente motivar os comportamentos de compra e recompra do produto (NICOLAO et al., 2016).

Já para o âmbito empresarial, a pesquisa irá auxiliar na tomada de decisão de empreendedores que operam no espaço online, pois permite obter conhecimentos sobre os estímulos ativadores presentes no Instagram e como eles atuam na mente dos consumidores (HEINONEN, 2011; TING et al., 2015). Ao se informar sobre as ações que compõem o processo de ativação do consumo, os empreendedores poderão utilizá-las em suas estratégias 
empresariais. De acordo com Zampier e Takahashi (2011), essa capacidade de visualizar o ambiente que antecede a criação de estratégias de uma empresa ampara o processo de decisão, sendo é fundamental para os empreendedores.

\section{Referencial Teórico}

Os seres humanos são constantemente influenciados pelo ambiente social em que vivem, as pessoas com quem convivem e os objetos que possuem. Como consequência, essas exposições podem afetar o comportamento dos indivíduos, encorajando-os a realizarem uma reação subsequente como resposta a esse estímulo (PACHECO JUNIOR; DAMACENA; BRONZATTI, 2015; SOLOMON, 2016). Esse processo de reação é chamado de priming.

O priming consiste em uma preparação para o momento de decisão do indivíduo (MIRSCH; LEHRER; JUNG, 2017). É caracterizado por uma exposição prévia a um determinado estímulo, podendo influenciar seus processos mentais, e ocasionar uma resposta automática, sem que exista consciência sobre tal influência (PACHECO JUNIOR; DAMACENA; BRONZATTI, 2015; MARLET; BATISTA, 2017). Em outras palavras, o priming é um estímulo capaz de ativar representações mentais e desencadear ações futuras, influenciando atitudes de consumo, comportamentos e decisões (GALVÃO; LUCENA; PRADO, 2016).

Na perspectiva do comportamento do consumidor, Solomon (2016, p. 58) destaca que o priming faz parte da tomada de decisão habitual do consumidor, que se refere "[...] as escolhas feitas com pouco ou nenhum esforço consciente". Esse processo ocorre por meio de associações entre um estímulo e todas as ideias relacionadas a ele (FAZIO et al., 1986), ou seja, quando um indivíduo é exposto a um estímulo específico, como imagens que fazem referência a produtos e marcas, é ativada automaticamente a ideia e o desejo de consumo, fazendo com que assuma comportamentos subsequentes, como o ato de realizar a compra.

O processo de ativação pode ser consciente e supraliminar, baseado na memória explícita, ocorrendo quando o executor percebe e retorna automaticamente à fonte inicial do estímulo, ou inconsciente e subliminar, baseado na memória implícita, que ocorre quando o estímulo só é percebido em nível inconsciente e o executor age sem esforço da memória e de forma espontânea (LEE, 2002; GALVÃO; LUCENA; PRADO, 2016).

Ainda nesse sentido, o tempo de exposição e atenção ao estímulo também podem interferir em uma ativação consciente e inconsciente (PACHECO JUNIOR; DAMACENA; BRONZATTI, 2015), o que implica dizer que longos períodos de atenção ao estímulo pode estimular a ativação consciente, já períodos curtos podem estimular a ativação inconsciente, pelo fato de não ter havido tempo suficiente para processar todas as informações, apesar de terem sido captadas (PACHECO JUNIOR; DAMACENA; BRONZATTI, 2015; GALVÃO; LUCENA; PRADO, 2016). No entanto, alguns autores afirmam que mesmo que o indivíduo consiga perceber os estímulos aos quais estão sendo expostos, eles não são capazes de perceber a influência que esses estímulos têm sobre seus comportamentos ou mesmo que o seu consumo esteja sendo ativado (DIJKSTERHUIS et al., 2005; PACHECO JÚNIOR; DAMACENA; BRONZATTI, 2015; MARLET; BATISTA, 2017).

Como foi mencionado anteriormente, os efeitos priming podem exercer influência na formação do comportamento, percepções e julgamentos dos indivíduos, mesmo que não sejam percebidos. Esses fatores podem ser visuais, auditivos, olfativos e podem ativar 
temporariamente uma tendência de resposta (TATE; STEWART; DALY, 2014; NICOLAO et al., 2016). Diante disso, o priming pode ocasionar uma ativação por meio de três formas, quais sejam: afetiva ou emotiva; comportamental ou motivacional; e cognitiva ou semântica.

O priming afetivo envolve estímulos não intencionais, como sentimentos e emoções relacionadas a uma ideia. Na maioria das vezes o efeito afetivo ocorre com imagens e cores, como por exemplo, símbolos relacionados ao amor e cores que representam a alegria. Além disso, as imagens são responsáveis por produzir mais estímulos afetivos do que as palavras, isso porque apelam para os sentidos e menos a racionalidade (TATE; STEWART; DALY, 2014; MINTON; CORNWELL; KAHLE, 2016).

O priming comportamental envolve intenções comportamentais que são ativadas por meio de informações que ficam mantidas na memória e só são associadas quando o indivíduo se depara com o objeto ou contexto (PACHECO JUNIOR; DAMACENA; BRONZATTI, 2015). Um exemplo disso, no contexto do comportamento do consumidor, é a motivação que um indivíduo recebe para realizar uma ação de compra de um produto de alta qualidade e socialmente aceito logo após ver o logotipo da Apple ou quando passa a ter hábitos mais saudáveis ao ser constantemente exposto a propagandas de academia ou cartazes com receitas vegetarianas (MINTON; CORNWELL; KAHLE, 2016).

Por último, o priming cognitivo refere-se às mudanças de pensamento com base na presença de um estímulo. É também conhecida como uma ativação semântica, pois também pode ser impulsionada por palavras, frases, sinais, símbolos, que influencia uma resposta/ação. Nos campos de estudos do marketing e comportamento do consumidor, a ativação cognitiva e semântica é utilizada para medir o que o consumidor pensa depois de ter sido exposto a um estímulo (MINTON; CORNWELL; KAHLE, 2016), ou seja, a avaliação do consumidor a respeito da marca ou produto e suas experiências pessoais.

Outro tipo é mencionado por Pacheco Junior, Damacena e Bronzatti (2015) e Dijksterhuis et al., (2006), o priming social, que é constituído por representações sociais de pessoas, também pode ser considerado um estímulo ativador. Nesse caso, pessoas associadas a outras podem levar a ativação automática de uma ação, como por exemplo, ao observar o comportamento de parentes, amigos e pessoas importantes, o indivíduo pode automaticamente começar a agir como essas pessoas e ter os mesmos hábitos de consumo (DIJKSTERHUIS et al., 2006).

Sobre a ocorrência da ativação, nota-se que ela pode acontecer de forma imediata, em função de memórias recentes de estímulos isolados ou em função da repetição de estímulos, ocasionando um excesso de exposição ao longo do dia a dia do consumidor, o que torna o processo mais consistente (PACHECO JUNIOR; DAMACENA; BRONZATTI, 2015; MINTON; CORNWELL; KAHLE, 2016; NICOLAO et al., 2016). Entretanto, é importante esclarecer que um estímulo sozinho não é capaz de gerar uma ação, sendo preciso que haja representações mentais pré-existentes para que a ideia seja ativada (GALVÃO; LUCENA; PRADO, 2016), ou seja, o indivíduo já deve ter o interesse de consumo internalizado para que seja, de fato, ativado após a exposição.

No contexto das redes sociais, compreende-se que a ativação do consumo pode ser motivada pela combinação de estímulos visuais, textuais, comportamentais e sociais, visto que é composta por imagens, legendas, experiências e rede de contatos das quais os usuários já apresentam uma certa afinidade. Essa afinidade pode ser ressaltada por meio dos algoritmos, mecanismos que agem como "filtro bolha", separando informações, ideias, pessoas e anúncios 
publicitários para cada utilizador, com base nos seus hábitos de consumo em seus perfis virtuais (FAVA; PENÍSIA JÚNIOR, 2017). Para confirmar esse pensamento, Mirsch, Lehrer e Jung (2017) analisaram fotos de usuários da rede social Instagram e constataram que imagens publicadas por perfis seguidos compartilhando momentos, opiniões, demonstrações de produtos e recomendação de marcas podem ativar o interesse do consumidor, estimulando-o a tomar a decisão de também consumir.

\section{$3 \quad$ Procedimentos Metodológicos}

Nesta esta investigação, optou-se pela pesquisa de abordagem qualitativa, que busca a compreensão de um fenômeno, baseando-se na coleta de informações, interpretação e descrição de sujeitos e o seu contexto (STAKE, 2011; GODOY, 1995a). Aborda detalhadamente os comportamentos, crenças, valores e atitudes, o que corresponde a um espaço mais profundo das relações, dos processos e dos fenômenos que não podem ser medidos ou quantificados (MINAYO, 2001).

Para obter as informações a fim de responder à pergunta da pesquisa, optou-se por realizar um estudo de caso, conceituado por Yin (2015) como uma pesquisa empírica, realizada de forma minuciosa e aprofundada sobre um tema contemporâneo, desenvolvido diante do desejo de se compreender a sociedade. É realizado quando o pesquisador apresenta pouco controle acerca dos eventos ocorridos, entretanto, permite revelar amplo e detalhado conhecimento sobre algum fato real do presente (GODOY, 1995b). Assim, esta é uma pesquisa de abordagem qualitativa, desenvolvida a partir de um estudo de caso com usuários do Instagram.

Por se tratar de um estudo de caso qualitativo, foram utilizadas entrevistas semiestruturadas (COPPER; SCHINDLER, 2011) como técnica de coleta de dados, por ser considerada "[...] uma estratégia fundamental da investigação qualitativa" (GODOY, 1995a, p. 61). Em vista disso, essa pesquisa utilizou dois tipos de entrevistas, sendo realizadas em duas etapas distintas: entrevista em grupo e entrevista individual. Anteriormente ao período de coleta de dados, os dois roteiros de entrevistas foram validados e aprimorados na fase do estudo piloto.

Dessa forma, a entrevista em grupo foi realizada na primeira etapa da coleta de dados, no dia 27 de setembro de 2018, com um grupo de 6 pessoas e seguiu um roteiro para obter ampla variedade de informações em um curto período de tempo (COOPER; SCHINDLER, 2011). A entrevista durou cerca de 1 hora e 24 minutos e foi conduzida por uma das pesquisadoras com o intuito de realizar a mediação e registrar as informações, além disso foram usados dois gravadores que colaboraram na transcrição da entrevista posteriormente.

Para participar da entrevista em grupo foram determinados os seguintes critérios: a) ser maior de 18 anos e b) ser usuário da rede social Instagram. Com isso, a entrevista foi composta por 6 sujeitos heterogêneos, isto é, com variedade de opiniões, histórico de vida e comportamentos diferentes (COOPER; SCHINDLER, 2011), totalizando 3 mulheres e 3 homens, com idades entre 21 e 39 anos, sendo 5 respondentes do Rio Grande do Norte e 1 do Ceará. Todos são estudantes do curso de Publicidade e Propaganda da UERN e trabalham na área, permitindo o acesso à temática abordada.

Como forma de ampliar as respostas e obter informações mais específicas e detalhadas sobre as experiências dos usuários na rede social Instagram, realizou-se a etapa 2, constituída por entrevista semiestruturada individual com 27 pessoas originadas de cada estado brasileiro, em momentos isolados e horários pré-agendados, e também seguiu um roteiro de entrevista 
semiestruturada. Como forma de alcançar todos os sujeitos da pesquisa, as entrevistas ocorreram presencialmente, via Skype, Whatsapp e por telefone, foram gravadas e transcritas, totalizando 684 minutos.

Portanto, nessa fase foram entrevistados 27 sujeitos correspondentes a cada estado do Brasil, sendo 21 mulheres e 6 homens, com idade entre 18 e 50 anos. Os respondentes ainda possuem diferentes níveis de escolaridade e profissão/ocupação, o que contribui na abrangência e diferenciação das respostas coletadas.

É importante esclarecer que o critério de seleção dos sujeitos foi do tipo bola de neve, que utiliza cadeias de referência dos participantes já existentes (FLICK, 2009). Dessa forma, os respondentes da pesquisa indicaram novos contatos de sua rede pessoal com as características desejadas da pesquisa para participar das entrevistas. Já sobre a quantidade exata de participantes das sessões de entrevistas individuais foi definida quando se obteve a saturação das informações, que ocorre quando não há mais novidade nas respostas coletadas (PAIVA JUNIOR; LEÃO; MELO, 2011).

Após a fase de coleta de dados foi iniciada a análise, considerada por Gomes (2001) como a etapa de tratamento dos dados e interpretação dos resultados obtidos. Esta pesquisa adotou a técnica de análise de conteúdo para realizar a interpretação dos dados, auxiliando na descrição, inferência e interpretação (BARDIN, 2011) dos dados coletados nas entrevistas, buscando obter conexões com o referencial teórico abordado na pesquisa.

Ainda de acordo com Bardin (2011), a análise dos dados foi composta por três etapas fundamentais: pré-análise, exploração do material e tratamento dos resultados. A pré-análise é considerada a fase de organização. Nessa etapa, foi definido o escopo da pesquisa e realizada uma releitura do material, para retirar os erros de digitação e vícios de linguagem dos respondentes.

A exploração do material é a fase de administração das decisões tomadas na pré-análise. Consiste na leitura aprofundada do material, buscando codificar, classificar e categorizar (BARDIN, 2011). É oportuno ressaltar que nessa fase, no momento da codificação, foram levantados alguns construtos para enriquecer a análise. Para isso, foi definido o recorte, que corresponde a escolha das unidades de registro, os quais foram selecionadas palavras-chave e os temas mais recorrentes (BARDIN, 2011).

A última etapa corresponde ao tratamento dos resultados obtidos e interpretação. Para Bardin (2011), essa é a fase de tratar os dados de modo que sejam significativos e válidos. Utiliza técnicas qualitativas e/ou quantitativas para ajudar na interpretação, buscando confirmar os pressupostos da pesquisa e alcançar os objetivos inicialmente propostos. Para isso, foram utilizadas, nesta pesquisa, redes para auxiliar na interpretação dos resultados.

Ressalta-se que na etapa de análise dos dados foi utilizado o ATLAS.ti na versão 8, ferramenta que contribui para a realização de pesquisas que aplicam a análise de conteúdo (WALTER; BACH, 2015). Dentre as funcionalidades do ATLAS.ti está o tratamento de grande quantidade de informações, o que facilita a sua operacionalização e, consequentemente, o trabalho do pesquisador (LEITE; MORAES; SALAZAR, 2016), pois torna o processo mais ágil. Com o programa, foi possível acessar as transcrições, analisar, codificar e categorizar as respostas dos entrevistados.

\section{$4 \quad$ Análise dos Resultados}


Esta seção tem como propósito identificar se o consumo pode ser ativado no Instagram. Assim sendo, com base na análise dos dados foi observado que o consumo dos entrevistados nas redes sociais digitais pode ser ativado de forma consciente, isto é, os usuários ao serem expostos aos estímulos, no caso as publicações do Instagram, guardam as informações em sua memória externa e ao realizarem a ação subsequente (o ato de compra) retornam automaticamente à fonte inicial do estímulo.

A figura 1 apresenta a rede correspondente ao primeiro objetivo específico com base nas respostas concedidas pelos entrevistados. A rede está dividida em 5 categorias principais: representações mentais; ocorrência da ativação; tempo de exposição e atenção ao estímulo; e, por fim, consciência da ativação.

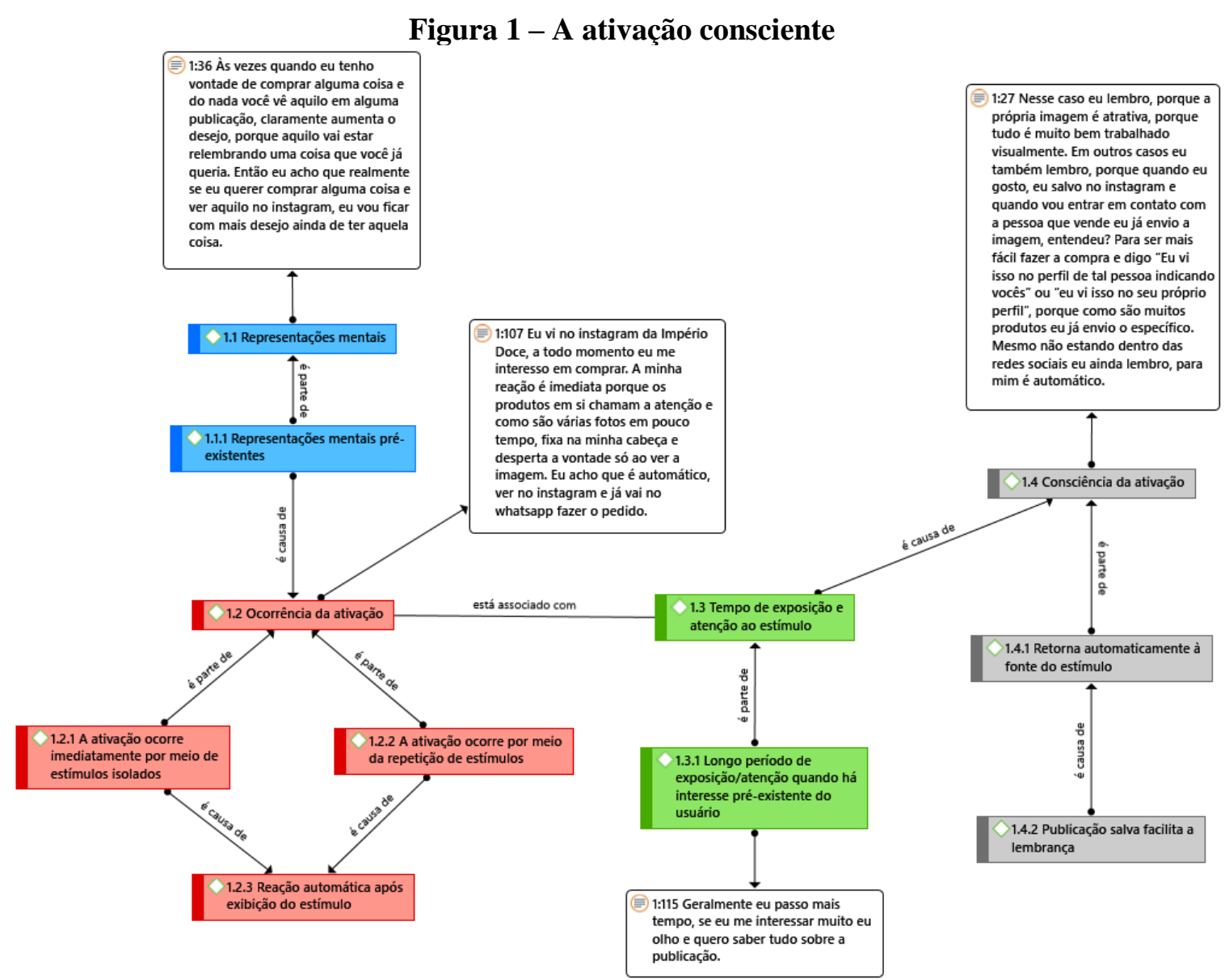

Fonte: Elaboração das autoras com ATLAS.ti (2019).

A primeira categoria mencionada se refere às representações mentais dos usuários, que são ativadas em decorrência dos vários estímulos expostos, afetando diretamente o comportamento posterior e a tomada de decisão dos consumidores (ESCALAS; BETTMAN, 2003; DIJKSTERHUIS et al., 2005; TSALIKIS; PERALTA, 2014; PACHECO JÚNIOR; DAMACENA; BRONZATTI, 2015; GALVÃO; LUCENA; PRADO, 2016). Sobre isso, os entrevistados relataram que se sentem atraídos a consumir ao serem expostos a publicações com 
conteúdo, produtos e serviços dos quais eles já tinham interesse prévio, como é possível observar no relato a seguir:

\begin{abstract}
Uma vez eu estava no meu Instagram e vi uma foto de uma amiga usando um estetoscópio, um dos mais caros que tem no mercado. Eu já estava pensando em comprar o meu para as fotos da minha placa de formatura, mas pretendia comprar um mais barato, até porque não iria usar muito. Só que ao ver aquela publicação eu quis comprar exatamente aquele estetoscópio. Na mesma hora que olhei, já falei com a minha mãe e acabei comprando (Entrevistado 13_PA).
\end{abstract}

Isso implica dizer que ativação do consumo ocorre quando há representações mentais préexistentes, ou seja, a ideia de consumo já estava internalizada nos usuários, contudo, a imagem publicada contribui para reforçar ainda mais a tomada de decisão e a ação de compra subsequente. Esse resultado corrobora os pensamentos dos autores, que afirmam que os estímulos não são capazes de criar um estado motivacional nos sujeitos, mas apenas quando há representações mentais já existentes (PACHECO JÚNIOR; DAMACENA; BRONZATTI, 2015).

Foi possível identificar que essas representações mentais pré-existentes estão ligadas ao chamado "filtro bolha", isso porque o Instagram dá a possibilidade de os usuários verem somente as publicações e o conteúdo que eles querem (Entrevistada 21_BA), permitindo-os que fiquem em sua bolha construída com base em suas preferências na rede social (STACEY; PAUWELS; LACKMAN, 2013; CORRÊA; BERTOCCHI, 2012; FAVA; PENÍSIA JÚNIOR, 2017). Dessa forma, pode-se dizer que os usuários tendem a olhar em seu perfil aquilo que já era de interesse, contribuindo mais para ativação.

As representações mentais são consideradas a base da ocorrência da ativação (PACHECO JÚNIOR; DAMACENA; BRONZATTI, 2015), segunda categoria a ser citada. Para uma parte dos entrevistados, a ativação é desencadeada imediatamente, logo após a exibição de estímulos isolados, o que implica dizer que, o desejo de consumo é despertado no momento em que o usuário visualiza uma publicação sobre o produto/serviço, como expressa a Entrevistada 19_MS: "Uma vez vi uma publicação de uma amiga e na foto ela estava comendo uma torta muito bonita, parecia ser bem gostosa. Aí eu curti a foto, na mesma hora perguntei onde era o lugar e depois eu fui lá comprar. Não cheguei a comprar no mesmo dia, mas a vontade bateu na hora". Essa ideia está em concordância com a teoria, visto que o efeito imediato, no qual é baseado na memória recente do sujeito é considerado uma das formas de ocorrência da ativação (GALVÃO; LUCENA; PRADO, 2016; MINTON, CORNWELL; KAHLE, 2016). Ainda podese dizer que esse evento também confirma o pensamento de Lee (2002), pois as exposições recentes resultam em maior probabilidade de escolha, pelo fato de ser realizado em curto período de tempo.

A segunda forma de ocorrência da ativação foi citada pela outra parte dos entrevistados, a ativação pela repetição de estímulos. Nesse caso, foi expresso que ao passo que o mesmo estímulo é exposto mais de uma vez em momentos alternados dos dias, a intenção de consumo vai sendo idealizada e reforçada até que haja, de fato, a ativação, como assim explica a Entrevistada 22_AC:

[...] se eu vejo que um produto está sendo bem falado, está muito na moda e muitos amigos estão publicando foto usando a mesma coisa, eu sinto vontade de ter também, 
surge um desejo inconsciente de também fazer parte daquele universo, daquele estilo de vida e aí eu sempre acabo comprando mais.

Com isso, no relato anterior, a entrevistada comenta que só depois de ver várias publicações com imagens e comentários a respeito de um produto específico ela teve interesse em consumir o que estava sendo exposto. Ainda complementando, há casos em que o usuário retorna à publicação de forma intencional para visualizar novamente as informações, como detalha a Entrevistada 20_AL, o que também se considera uma ativação por repetição, pelo fato do estímulo estar sendo visto mais de uma vez. E, por isso, essa forma de ativação também é considerada eficaz devido ao fato da exposição repetida aumentar a preferência do usuário, por estar mais familiarizado com o conteúdo (PACHECO JÚNIOR; DAMACENA; BRONZATTI, 2015; MINTON; CORNWELL; KAHLE, 2016; NICOLAO et. al., 2016).

Ainda nessa categoria foi possível observar que independentemente da forma como ocorre a ativação, seja imediata ou por repetição, ambas são responsáveis por motivarem uma reação automática após a exibição do estímulo, que pode ser a busca por mais informações, a comunicação direta com a loja, o arquivamento (printscreen) da imagem ou mesmo a compra do produto. Dessa forma, comprova-se que o processo de ativação é responsável por influenciar comportamentos e ações subsequentes dos usuários como resposta a esses estímulos (FAZIO et al., 1986; DIJKSTERHUIS et al., 2005; MARTIN; MORICH, 2011; PACHECO JÚNIOR; DAMACENA; BRONZATTI, 2015; MINTON, CORNWELL; KAHLE, 2016; MIRSCH; LEHRER; JUNG, 2017).

A ocorrência da ativação está associada ao tempo de exposição e atenção ao estímulo, isso porque a frequência com que a imagem é visualizada tem relação com a quantidade de tempo necessária para que o desejo seja despertado. Sobre esse quesito, observa-se, por meio da análise, que a ativação ocorre devido aos longos períodos de tempo de exposição e atenção aos estímulos, contudo, isso só acontece devido ao interesse prévio dos usuários. Isso quer dizer que se o usuário já tiver predisposição e interesse prévio no conteúdo e/ou produto que está sendo divulgado, ele passará mais tempo visualizando e atento aos detalhes da publicação. Por outro lado, se não houver interesse, o usuário não dará atenção ao estímulo e logo passará para outra publicação, sem permitir que as informações sejam absorvidas (Entrevistada 6). Com isso, cabe dizer que os usuários entrevistados do Instagram são expostos por mais tempo às publicações, processando as informações com mais consciência e maior envolvimento, caso estejam interessados no produto, como menciona a Entrevistada 1: "[...] se eu me interessar eu olho e quero saber sobre tudo, como uma vez que uma amiga fez uma publicação em uma pousada lá em Canoa Quebrada e eu fiquei curiosa, porque estava pensando em ir. Então eu passei muito tempo olhando as fotos, os comentários, localizações e avaliações". Esse acontecimento confirma que quanto maior o envolvimento com o estímulo e suas informações, mais forte será a ativação e as ações seguintes, além de ter um processo de decisão mais eficiente (LEE, 2002; DIJKSTERHUIS et al., 2005; NICOLAO et. al., 2016; GALVÃO; LUCENA; PRADO, 2017).

Longos períodos de exposição ao estímulo são considerados suficientes para que haja uma ativação em nível consciente (PACHECO JÚNIOR; DAMACENA; BRONZATTI, 2015). Sobre esse aspecto, os entrevistados relataram que o processo de ativação acontece conscientemente, com esforço da memória, já que eles retornam à fonte inicial do estímulo, isto é, no momento da compra os usuários lembram da publicação que despertou o seu desejo de 
consumo e ainda se recordam dos detalhes que a envolvem, como o amigo que publicou, o produto, o lugar, a roupa etc. De um modo mais detalhado, a Entrevistada 26_RR revela:

\begin{abstract}
Consigo lembrar da publicação sim, uma vez umas colegas minhas postaram fotos e marcaram uma loja daqui. Aí no período da Black Friday eu vi a propaganda dessa loja com algumas promoções e fui lá ver, aí no dia que eu fui eu lembrei que uma dessas meninas estava vestindo a mesma roupa dessa loja em uma foto no Instagram. Eu lembro, na mesma hora eu lembro e penso 'ah, essa roupa é a que fulana de tal estava vestindo'.
\end{abstract}

Isso acontece porque no momento em que a publicação foi exposta pela primeira vez, houve atenção às informações e essas informações foram armazenadas na memória explícita do usuário, sendo facilmente resgatada no momento em que o usuário decide agir, como confirmam Hsu (2012) e Pacheco Júnior, Damacena e Bronzatti, (2015).

Ainda foi possível identificar que uma das formas que auxiliam na ativação consciente é a ferramenta "salvos" do Instagram ou a ferramenta printscreen do celular. Esses recursos são responsáveis por arquivar as publicações ou imagens que o usuário tem mais interesse para que em outro momento possam vê-las novamente e lembrar-se das informações contidas nelas, como explica a Entrevistada 14_MT: "Eu costumo associar o produto à publicação sim, principalmente devido à ferramenta de salvar. O que me interessa, eu salvo para não esquecer e quando surgir uma oportunidade eu compro". Nesse caso, essa reação é caracterizada como uma ativação consciente ocorrida por meio da repetição do estímulo, pois a usuária ao se interessar pelo produto salva a publicação para não esquecer e retornar posteriormente no momento da compra. Pode-se dizer, então, que as publicações salvas reforçam a ativação consciente, pois são visualizadas com mais frequência, permitindo o processamento das informações (MARTIN; MORICH, 2011; PACHECO JÚNIOR; DAMACENA; BRONZATTI, 2015; MINTON; CORNWELL; KAHLE, 2016).

Observou-se também a percepção dos usuários quanto à influência das publicações dos perfis seguidos sobre seus comportamentos e intenção de compra. O resultado dessa análise é ilustrado na Figura 2. 
Figura 2 - Percepção da influência da ativação

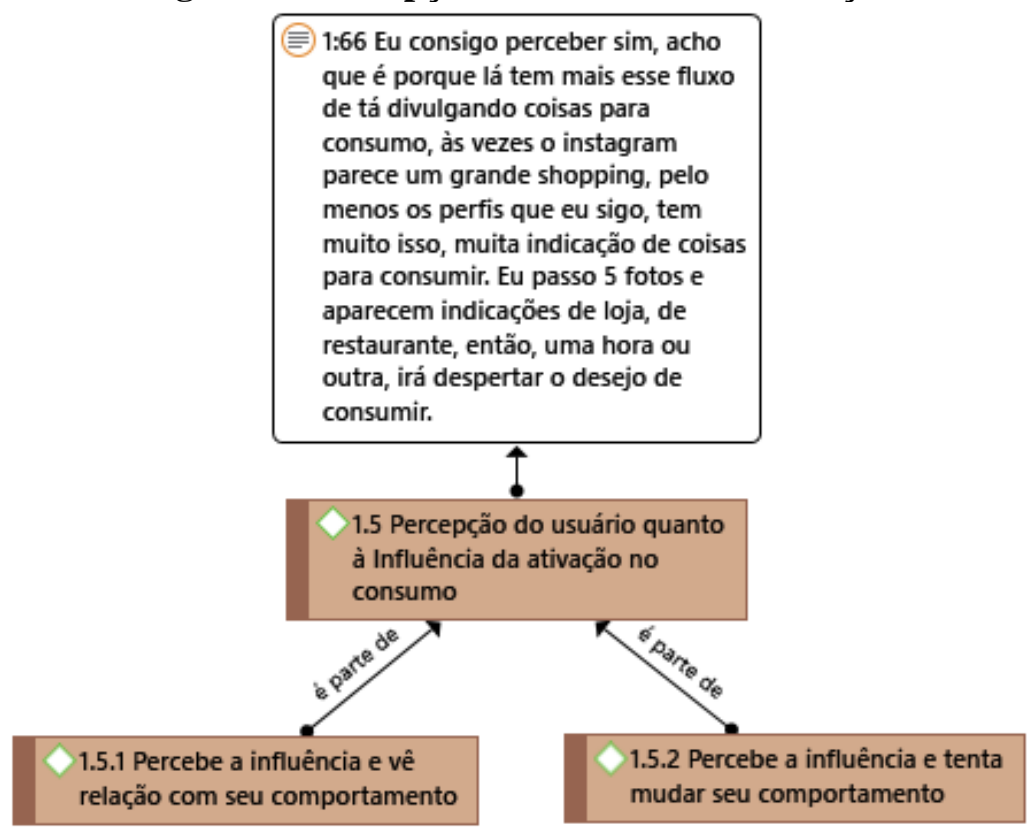

Fonte: Elaboração das autoras com ATLAS.ti (2019).

Sobre essa categoria, os respondentes declaram que conseguem perceber a influência que as publicações de seus amigos virtuais têm sobre suas reações, tendo consciência que as imagens nas quais são expostos estimulam ainda mais o seu consumo, como mostra o depoimento a seguir: "Aqui em Brasília está tendo uma febre de cafezinhos. De café gourmet, café da manhã assim mais diferente, e eu acho que o fato das pessoas postarem muito isso no Instagram, mudou um pouco meu comportamento, porque agora todo sábado e domingo eu estou em um cafezinho desses" (Entrevistado 30 GO). Nesse caso, eles conseguem identificar o estímulo, como também conseguem ter conhecimento que esse estímulo pode modificar seu comportamento. Por sua vez, esse resultado confronta com o pensamento de alguns autores, que afirmam que mesmo se a ativação for consciente, não é possível perceber a sua influência sobre as suas ações (DIJKSTERHUIS et al., 2005; PACHECO JÚNIOR; DAMACENA; BRONZATTI, 2015; MARLET; BATISTA, 2017). Contudo, observa-se que está em concordância com a ideia de que quando a influência é percebida e reconhecida há a necessidade de correção do comportamento, a fim de amenizar o efeito, como bem enfatiza a Entrevistada 27_AP: "Eu já passei a agir igual a uma pessoa que eu seguia. Eu assistia muito os Stories dela, ficava vendo o que ela estava fazendo o tempo todo, aí eu comecei a agir como ela no modo de agir e até de comprar. Quando eu percebi isso, achei muito estranho e parei". Ainda é importante esclarecer que essa situação de correção relatada pela usuária apenas ocorre quando a influência percebida afeta negativamente o seu desempenho (GALVẪ; LUCENA; PRADO, 2016; NICOLAO et al., 2016).

Com isso, esses resultados apontam a possibilidade dos estímulos compartilhados na rede social Instagram serem responsáveis por impulsionar a ativação do consumo nos usuários, de forma consciente, sendo possível perceber a sua influência dos comportamentos subsequentes.

\section{Considerações Finais}


A partir da análise dos resultados, é possível fazer algumas considerações. A primeira delas é de que foi possível identificar que no Instagram são encontrados variados estímulos externos que podem ativar o consumo dos usuários e influenciar o comportamento de compra de forma intencional, pelo fato de acessarem essa rede propositalmente, isto é, já com o intuito de acompanhar pessoas e conteúdos aspiracionais, buscando informações de produtos/serviços que satisfaçam suas necessidades pessoais.

Com isso, notou-se que os usuários estão cada vez mais conscientes das suas ações nas redes sociais, sendo possível perceber não só os estímulos aos quais estão expostos, como também a influência desses em seus sentimentos, ações e comportamentos subsequentes. Tal constatação foi corroborada pelos entrevistados, que confirmaram estarem atentos às publicações que mais os atraem e despertam seu interesse de compra, conseguindo elencar facilmente as informações contidas no imagem, como pessoa, lugar, vestuário, produtos que estão sendo indicados/usados, o que caracteriza como um retorno à publicação de forma espontânea, porém consciente.

Ainda ficou evidenciado que esse fácil acesso às lembranças das publicações é reforçado pelos próprios recursos presentes no Instagram, como a categoria de "salvos". Esse recurso foi bastante comentado pelos entrevistados por ser uma ferramenta que recorrem quando querem gravar o conteúdo para rever em outros momentos e também retornar quando sentem a necessidade de recordar o que já foi visto. Entende-se que isso faz com que os usuários processem as informações de forma mais eficiente, pelo fato de haver a repetição da exibição, contribuindo para uma ativação consciente.

Ainda nesse sentido, observa-se a presença de uma divergência entre os resultados obtidos e a literatura, em relação à percepção da ativação. Isso se deve ao fato dos entrevistados serem perceberem as influências que as publicações têm sobre seu comportamento de compra, sendo que a maioria reconhece que passou a consumir mais após se tornar ativa na plataforma e criar uma relação próxima aos seus amigos virtuais. Ademais, compreende-se que além da influência ser percebida, é aceita e vista como uma forma de direcionar melhor o consumo, fazendo com que os usuários estejam sempre informados sobre as novidades relacionadas aos conteúdos de seu interesse, como, por exemplo, a apresentação de um novo produto ou lugar. É importante reforçar que essa influência é bem recebida de modo que não provoque nenhum dano ou efeito negativo, como o de comprar compulsivamente ou mais do que seu orçamento permite, caso isso aconteça essa influência é diminuída e a ação derivada dela é rapidamente corrigida.

Nesse sentido, os achados permitem responder à problemática da pesquisa, compreendendo que as publicações dos amigos virtuais seguidos do Instagram podem ativar conscientemente o consumo dos usuários. Contudo, os resultados obtidos estão em consonância com o entendimento que essa ativação apenas ocorre se já houver interesse prévio e afinidade dos usuários com os hábitos e comportamentos de seus amigos, não sendo capaz de criar novas representações mentais.

De uma perspectiva teórica, esta investigação traz algumas contribuições para a academia. Em primeiro lugar, por evidenciar a ativação consciente, visto que outras pesquisas trouxeram vasto apanhado teórico a respeito da ativação inconsciente. A segunda contribuição é por trazer a discussão sobre o processo de ativação do consumo no contexto das redes sociais digitais. Isso implica dizer que os resultados desse estudo proporcionaram um conhecimento que vai além da literatura existente, revelando como ocorre a ativação do consumo, por meio 
de quais perspectivas e os seus efeitos no comportamento dos sujeitos que utilizam essas plataformas.

As limitações do estudo se apresentam em virtude de haver poucas pesquisas envolvendo a ativação do consumo, principalmente no ambiente digital, o que pode ter limitado o levantamento teórico acerca da temática.

Como sugestões para trabalhos futuros, indica-se a necessidade de se aprofundar sobre o tema e compreender se a ativação do consumo pode ser estimulada por aspectos emocionais, comportamentais, representações sociais e mudança de percepção dos usuários. Além disso, propõe-se a realização de uma análise quantitativa para trazer à tona descobertas a respeito do efeito dessa ativação no aumento do consumo.

E por fim, também é importante sugerir a realização de uma investigação que faça com que o pesquisador acesse as informações inconscientes dos usuários do Instagram, percebendo como essa perspectiva influi em seu comportamento de consumo. Diante disso, os resultados desta pesquisa revelam a necessidade de realizar mais estudos envolvendo o priming virtual e ativação do consumo nas redes sociais, de modo a ampliar o conhecimento científico.

\section{Referências}

BARDIN, L. Análise de Conteúdo. Lisboa: Edições 70, 2011.

CASALÓ, L. V; FLAVIÁN, C; IBAÑEZ, S. Antecedents of consumer intention to follow and recommend an Instagram account. Online Information Review, v. 41, n. 7, p. 1046-1063, 2017.

COOPER, D. R.; SCHINDLER, P. S. Métodos de pesquisa em administração. $10^{a}$ ed. Porto Alegre: Bookman, 2011.

CORRÊA, E. S; BERTOCCHI, D. O Algoritmo Curador: O papel do comunicador num cenário de curadoria algorítmica de informação. In: XXI Encontro Anual da Compós - Associação Nacional dos Programas de Pós-Graduação em Comunicação, Juiz de Fora/MG, 2012.

DI PIETRO, L; PANTANO, E. An empirical investigation of social network influence on consumer purchasing decision: The case of Facebook. Journal of Direct, Data and Digital Marketing Practice, v. 14, n. 1, p 18-29, 2012.

DIJKSTERHUIS, A; SMITH, P. K; BAAREN, R.B.V; WIGBOLDUS, D. H. J. The unconscious consumer: effects of environment on consumer behavior. Journal of Consumer Psychology, v. 15, n. 3, p. 193-202, 2005.

DJAFAROVA, E; RUSHWORTH, C. Exploring the credibility of online celebrities' Instagram profiles in influencing the purchase decisions of young female users. Computers in Human Behavior, v. 68, n.1, p. 1-7, 2017.

FAZIO, R. H; SANBONMATSU, D. M; POWELL, M. C; KARDES, F. R. On the Automatic Activation of Attitudes. Journal of Personality and Social Psychology, v. 50 n. 2, p. 229-238, 1986.

FAVA, G; PENÍSIA JÚNIOR, C. Filtro bolha: Como tecnologias digitais preditivas transformam a comunicação mediada por computador. Revista Eco Pós, v. 16, n. 2, p. 275-294, 2017.

FLICK, U.. Uma introdução à pesquisa qualitativa. 3. ed. Porto Alegre: Bookman, 2008. 
GODOY, A. S. Introdução à pesquisa qualitativa e suas possibilidades. Revista de Administração de Empresas, São Paulo, v. 35, n. 2, p. 57-63, mar./abr. 1995a.

GODOY, A. S. Pesquisa qualitativa tipos fundamentais. Revista de Administração de Empresas, São Paulo, v. 35, n.3, p. 20-29, Mai./Jun. 1995b.

HERMIDA, A. FLETCHER, F; KORRELL, D; LOGAN, D. Your Friend as Editor: The Shift to the Personalized Social News Stream. In: The Future of Journalism Conference. Cardiff: Cardiff University, 2011.

HEINONEN, K. Consumer activity in social media: Managerial approaches to consumers' social media behavior. Journal of Consumer Behaviour, v. 10, n. 6, p. 356-364, 2011.

HSU, C. The influence of cognitive and affective priming on banner ad attention and effect. In: 4th International Conference, Bangkok, Thailand, p. 36-41, 2015.

HU, Y.; MANIKONDA, L.; KAMBHAMPATI, S. What We Instagram: A First Analysis of Instagram Photo Content and User Types. In: Eighth International AAAI Conference on Weblogs and Social Media, Michigan, USA, p. 595-598, 2014.

LEE, A. Y. Effects Of Implicit Memory On Memory-Based Versus Stimulus-Based Brand Choice. Journal of Marketing Research, v. 39, n. 4, p. 440-454, 2002.

GALVÃO, F. H; LUCENA, D. M; Prado, P. H. M. Um Ensaio Teórico Sobre A Teoria De Priming No Contexto De Marcas Esportivas. REMark - Revista Brasileira de Marketing, v. 15, n. 1, p. 16-27, 2016.

MARLET, R. Q; BATISTA, L. L. Comunicação, Neurociência e a Recepção Não Declarada. Compós, v. 25, n. 1, p. 1-18, 2018.

MARTIN, N; MORICH, K. Unconscious mental processes in consumer choice: Toward a new model of consumer behavior. Journal of Brand Management, v. 18, n. 7, p. 1-23, 2011.

MINAYO, M. C. de S. Ciência, Técnica e Arte: O Desafio Da Pesquisa Social. In: MINAYO, M. C. de S. (Org.) Pesquisa Social. Teoria, método e criatividade. 18. ed. Petrópolis: Vozes, 2001.

MINTON, E. A; CORNWELL, T. B; KAHLE, L. R. A theoretical review of consumer priming: Prospective theory, retrospective theory, and the affective-behavioral-cognitive model. Journal of Consumer Behaviour, J. Consumer Behav, v. 16, n. 4, 2016.

MIRSCH, T; LEHRER, C; JUNG, R. Digital Nudging: Altering User Behavior in Digital Environments. In: 13th International Conference on Wirtschaftsinformatik, St. Gallen, Switzerland, p. 634-648, 2017.

NICOLAO, L; YORKSTON, E; BROCATO, BREI, V. A. Improving Consumer Decisions: The Conscious Use of Primes as Performance Enhancers. Brazilian Adnistration Review, v. 13, n. 1, p. 19-32, 2016.

PACHECO JUNIOR, J. C. S; DAMACENA, C; BRONZATTI, R. Pré-ativação: o efeito priming nos estudos sobre o comportamento do consumidor. Estudos e Pesquisas em Psicologia, v. 15, n. 1, p. 284-309, 2015.

PAIVA JÚNIOR, F. G. de; LEÃO, A. L. M. de S.; MELLO, S. C. B. de. Validade e Confiabilidade na Pesquisa Qualitativa em Administração. Revista de Ciências da Administração, v. 13, n. 31, p. 190-209, set/dez. 2011.

PRIMO, A. O aspecto relacional das interações na Web 2.0. E-Compós, Brasília, v. 9, p. 121, 2007. 
RECUERO, Raquel. Diga-me com quem falas e dir-te-ei quem és: a conversação mediada pelo computador e as redes sociais na internet. Famecos, Porto Alegre, n. 38, p. 118-128, 2009.

SOLOMON, Michael R. O comportamento do consumidor: comprando, possuindo e sendo. 12. ed. Porto Alegre: Bookman, 2016.

STACEY, E. C; PAUWELS, K. H; LACKMAN, A. Beyond Likes and Tweets: How Conversation Content Drives Store and Site Traffic. The Center for Measurable Marketing, v. 1, n. 1, 1-38, 2013.

STAKE, R. E. Pesquisa qualitativa: Estudando como as coisas funcionam. Porto Alegre: Penso, 2011.

TATE, K; STEWART, A. J; DALY, M. Influencing green behaviour through environmental goal priming: The mediating role of automatic evaluation. Journal of Environmental Psychology, v. 38, n. 1, p. 225-232, 2014.

TSALIKIS, J; PERALTA, A. V. Priming effects on business ethical decision making. International Journal on Strategic Innovative Marketing, v. 1, n. 1, p. 1-8, 2014.

WALTER, S. A; BACH, T. M. Adeus papel, marca-textos, tesoura e cola: inovando o processo de análise de conteúdo por meio do Atlas.ti. Administração: Ensino e Pesquisa Rio de Janeiro, v. 16, n. 2, p. 275-308, 2015.

YIN, R. K. Estudo de caso: planejamento e métodos. 5. ed. Porto Alegre: Brookman, 2016.

ZAMPIER, M. A.; TAKAHASHI, A. R. W. Competências empreendedoras e processos de aprendizagem empreendedora: modelo conceitual de pesquisa. Cadernos EBAPE, v. 9, p. 564$585,2011$. 